\title{
Penile Cancer pT1a TNM Finding v8
}

National Cancer Institute

\section{Source}

National Cancer Institute. Penile Cancer pT 1a TNM Finding v8. NCI Thesaurus. Code C140064.

Penile cancer with tumor without lymphovascular invasion or perineural invasion and is not high grade (i.e., grade 3 or sarcomatoid). (from AJCC 8th Ed.) 